University of Vermont

UVM ScholarWorks

Rubenstein School of Environment and Natural Rubenstein School of Environment and Natural Resources Faculty Publications

3-1-2012

\title{
Understorey diversity in southern boreal forests is regulated by productivity and its indirect impacts on resource availability and heterogeneity
}

\author{
Peter B. Reich \\ University of Minnesota Twin Cities \\ Lee E. Frelich \\ University of Minnesota Twin Cities \\ Richard A. Voldseth \\ North Dakota State University \\ Peter Bakken \\ Wisconsin Department Natural Resources \\ E. Carol Adair \\ National Center for Ecological Analysis and Synthesis
}

Follow this and additional works at: https://scholarworks.uvm.edu/rsfac

Part of the Climate Commons

\section{Recommended Citation}

Reich PB, Frelich LE, Voldseth RA, Bakken P, Adair EC. Understorey diversity in southern boreal forests is regulated by productivity and its indirect impacts on resource availability and heterogeneity. Journal of Ecology. 2012 Mar;100(2):539-45.

This Article is brought to you for free and open access by the Rubenstein School of Environment and Natural Resources at UVM ScholarWorks. It has been accepted for inclusion in Rubenstein School of Environment and Natural Resources Faculty Publications by an authorized administrator of UVM ScholarWorks. For more information, please contact scholarworks@uvm.edu. 


\title{
Understorey diversity in southern boreal forests is regulated by productivity and its indirect impacts on resource availability and heterogeneity
}

\author{
Peter B. Reich ${ }^{1 *}$, Lee E. Frelich ${ }^{1}$, Richard A. Voldseth ${ }^{2}$, Peter Bakken ${ }^{3}$ and E. Carol Adair ${ }^{4}$ \\ ${ }^{1}$ Department of Forest Resources, University of Minnesota, 1530 Cleveland Ave. No., St. Paul, MN 55108, USA; \\ ${ }^{2}$ Department of Soil Science, North Dakota State University, 1402 Albrecht Blvd., Fargo, ND 58102, USA; ${ }^{3}$ Wisconsin \\ Department of Natural Resources, 910 Highway 54, East Black River Falls, WI 54615, USA; and ${ }^{4}$ National Center for \\ Ecological Analysis and Synthesis, University of California Santa Barbara, 735 State Street, Suite 300, Santa Barbara, \\ CA 93101-5504, USA
}

\begin{abstract}
Summary
1. Understanding the relationship between species diversity and productivity is central to linking compositional and functional aspects of terrestrial ecosystems, and little is known about such issues in boreal forests. We used structural equation modelling (SEM) to test several hypotheses about direct and indirect influences of productivity, its correlate basal area, and resources on understorey vascular plant diversity on 2025 plots in 81 southern boreal forests in Minnesota, USA.

2. We first examined the hypothesis that increasing basal area reduces plot-scale species richness due to competitive exclusion from the most limiting resource, light. As expected, light pre-emption increased with total basal area, which directly reduced understorey species richness. However, complex relations between basal area, dominant understorey species, and resource supply to the understorey can also influence understorey communities. Hence, we addressed whether plots with low light availability in the understorey were associated with low abundance of dominant understorey species and alleviation of competitive exclusion of other understorey species. SEM results showed that low light decreased total understorey cover, alleviating resource competition from this stratum and thus increasing understorey species richness. Furthermore, the cover of four dominant understorey species was positively correlated with light availability and negatively correlated with plotscale species richness.

3. Aggregating data for the 25 plots at each stand, SEM showed that stand-scale species richness was positively influenced by light heterogeneity, which in turn increased with annual above-ground productivity.

4. Species richness was positively influenced by litter $\% \mathrm{~N}$, considered an index of nitrogen availability at the plot and stand scale.

5. Synthesis. These results suggest that understorey species richness in boreal forests is regulated by productivity, but is primarily mediated by the indirect effects of productivity of the dominant producers on resource availability and heterogeneity.
\end{abstract}

Key-words: above-ground net primary productivity, Picea mariana, Pinus banksiana, plantplant interactions, Populus tremuloides, southern boreal forest, species richness

\section{Introduction}

Characterizing and understanding patterns of species diversity remains an important goal in ecological science. There is an enormous theoretical and empirical literature regarding the factors regulating diversity at varying hierarchical and spatial scales. One important feature of the literature involves the rela-

*Correspondence author. E-mail: preich@umn.edu tionship between plant productivity and species richness. Although consensus remains elusive, it seems likely that patterns vary with both hierarchical and spatial scale, with different mechanisms explaining patterns at different scales (Chase \& Leibold 2002; Rajaniemi 2003; Oberle, Grace \& Chase 2009; Chase 2010). Gillman \& Wright (2006) concluded that at continental to global scales, species richness appears to be generally positively related to above-ground net primary productivity (ANPP), consistent with the species-energy hypothesis, 
although previous studies were less uniform in this view (Mittelbach et al. 2001; Waide et al. 1999) and different growth forms may differ in their responses (Oberle, Grace \& Chase 2009). In contrast, a seemingly bewildering array of species richnessANPP interaction patterns have been reported at local to landscape scales, which is the scale of interest in this study. The literature includes reports that the species richness-ANPP interaction has no pattern, a unimodal pattern, and a positive relationship; but also in some cases $U$-shaped and negative relationships (Waide et al. 1999; Gross et al. 2000; Gillman \& Wright 2006). Reasons for such variation in the species richness-ANPP interaction could involve distinct ways in which different drivers of species richness influence the drivers of ANPP, and vice-versa, as well as influences of other drivers on both diversity and productivity (Wardle et al. 1997; Gross et al. 2000; Rajaniemi 2003; Reich 2009; Jonsson \& Wardle 2010).

Despite this variety of observations, perhaps the most common belief (Rajaniemi 2003) is that the species richness-productivity relationship is fundamentally unimodal at the local scale, as observed patterns (except perhaps the $U$-shaped pattern) can be explained by a rise-and-fall unimodal model, with the specific pattern observed in any given study in part due to which segment of a complete productivity gradient, and how large a part, was examined. There is some consensus (Newman 1973; Grime 1977; Huston 1979; Tilman \& Pacala 1993; Rajaniemi 2003) that at extremely low productivity, species richness is also typically low, and both increase together up to a point. There is less consensus however, regarding the mechanisms at play, what happens to species richness as productivity rises further, and even less consensus regarding the mechanisms involved.

To a degree, many species richness-ANPP hypotheses agree (Rajaniemi 2003) that the increase phase of the unimodal species richness-ANPP curve occurs because few species can tolerate extremely low resource availabilities, and as productivity increases resource requirements are met for more and more species. There is also a degree of consensus about the decrease phase of the curve - that the effect of competition on diversity is increasingly negative with increasing productivity. The possible mechanisms are manifold (and plausibly complementary) and include competition intensity, resource heterogeneity, and population dynamics, among others.

The maintenance of plant diversity is an important conservation priority in cold temperate and boreal forests. Studies have attempted to characterize patterns of boreal plant species composition and diversity in relation to productivity and many other hypothesized drivers, such as disturbance (Wardle et al. 1997; Rees \& Juday 2002; Haeussler \& Bergeron 2004;Kembell, Wang \& Dang 2005; Jonsson \& Wardle 2010), time since disturbance (Hart \& Chen 2006, 2008), or meso- and macroscale environment (Legare et al. 2001; Chipman \& Johnson 2002). Similarly as shown for ponds (Chase \& Leibold 2003), rough comparisons of boreal forest data bases suggest that at the continental scale, the more productive, warmer southern boreal forests have greater total vascular plant species richness than less productive, colder northern boreal forests (Waide et al. 1999). However, this coupling of diversity and productivity at large geographic scales likely reflects macro-scale controls on both diversity and productivity, rather than the patch-to-stand scale relationship between the two (Waide et al. 1999; Chase \& Leibold 2003).

Unfortunately, according to Waide et al. (1999), for boreal forests, "data bases adequate for comparison of diversity and productivity at the local site and stand level do not exist'. Although there has been a flurry of activity regarding boreal forest diversity in the past decade or so (see citations above), few include direct measurements of ANPP. In one of the studies most closely targeted at this question, Chen, Legare \& Bergeron (2004) used site index as a surrogate for productivity of aspen stands in British Columbia and reported that vascular species richness increased with site index, perhaps due to greater spatial and resource heterogeneity on more productive sites. In an earlier study, greater stress and lower resource availability on smaller islands may have alleviated abundance of and competitive exclusion by a single dominant species, allowing greater diversity (Wardle et al. 1997).

Herein, we use a data base that includes vascular plant richness, ANPP, basal area, and measures of stand structure and resource availability to assess whether species richness is related to productivity in southern boreal forests at a patch to stand scale and whether those relations might instead be associated with patterns of resource availability or heterogeneity that might co-vary with productivity. Given that few prior forest species richness-productivity studies directly measured productivity at the stand scale or measured resource availability or stand structure at the patch scale, our current data base presents an opportunity to explore unresolved questions about species richness-productivity relationships.

To assess hypotheses about the relations of resource supply, productivity and forest diversity, we measured plant species richness, ANPP, biomass, basal area, light and indices of nitrogen $(\mathrm{N})$ status for 81 southern boreal forest stands. These stands include Populus tremuloides (trembling aspen), Pinus banksiana (jack pine), and Picea mariana (black spruce)-dominated forests. All stands were mixtures of the dominant with several other tree species. Given sampling protocols, some measures, such as ANPP, can only be expressed at the stand scale, but several other variables were measured in $9,10,15$ or 25 individual plots (depending on measure and year of measurement) at a fine scale (representing a patch or neighbourhood scale for understorey plants) within each of those stands and thus, can be expressed at both plot and stand scales. Such measures included understorey community composition and richness, overstorey basal area and its composition, light availability, and litter $\% \mathrm{~N}$ concentration, allowing us to assess these relationships at both plot (e.g. c. $2 \mathrm{~m}^{2}$ scale) and aggregate stand ( 25 plots within a $60 \times 60 \mathrm{~m}$ area) scales, and to use plot-to-plot heterogeneity in light availability as a metric of resource heterogeneity. We use structural equation modelling (Shipley 2002) to examine and synthesize the various hypothesized linkages.

Given the species richness-ANPP hypotheses noted previously, and what we know about patterns of species diversity in boreal forests (Wardle et al. 1997; Hart \& Chen 2006), how should understorey species richness vary with ANPP and light in boreal forests? We hypothesize that we will observe a nega- 
tive species richness-ANPP relationship and positive species richness-light and positive species richness-resource heterogeneity relationships, as follows.

Given our hypothesis that light is the primary resource limitation in these forests, increasing resource pre-emption by overstorey trees that reduce light to understorey species will reduce richness at the plot scale (Hart \& Chen 2008; Fig. 1). However, if decreasing light to the understorey reduces abundance of an understorey species that itself can pre-empt resources and competitively exclude other understorey species (Hart \& Chen 2006), this would increase understorey species richness. In addition, we hypothesize that nitrogen is a secondary resource for these plants in these systems, and as a belowground resource increasing $\mathrm{N}$ supply should alleviate impacts of decreasing light supply by making plants relatively more shade tolerant (as shown in Walters \& Reich 2000). Thus, species richness should be positively related to our surrogate for $\mathrm{N}$ availability (litter $\% \mathrm{~N}$ ). In turn, we hypothesize that litter $\% \mathrm{~N}$ should have positive influence on productivity and basal area, and vice-versa. Finally, if patches within a stand are heterogeneous in light availability, this will lead to higher aggregate stand scale species richness because of increasing plot-plot beta diversity, as suggested by Hart \& Chen (2008).

\section{Materials and methods}

\section{SITES}

Northeastern Minnesota represents the southwestern ecotone of the boreal forests of North America. We studied 25 plots on each of 81 stands, ranging in age from 19 to 133 years old and covering the range of variation in the most important cover types typically seen in southern boreal forests of central and eastern North America (see Reich et al. 2001 for more details). Data included in this study were collected between 1995 and 1997. The stands were classified into three forest types, two age classes (25-40, 70-100 years), and two modes of disturbance (crown fire, logging) leading to stand turnover and initiation (Reich et al. 2001). We selected stands of three cover types important in Minnesota and central Canada: aspen (Populus tremuloides Michx.), jack pine (Pinus banksiana Lamb.), and black spruce (Picea mariana [Mill.] BSP.). The two stand age classes were chosen because they were the only classes for which it was possible to find sufficient numbers of stands established after both logging and fire. As stand age and disturbance type prior to current stand origin had little impact on vascular plant species composition or diversity in this data set (Reich et al. 2001) and were not significant in the analyses reported herein, these attributes will be ignored henceforth in this study.

Although classified and selected based on the dominant canopy tree species, each stand contained a mixture of tree species (see Table 1 in Reich et al. 2001). The dominant species made up 70-85\% of the basal area on average. Aspen and jack pine stands were found on mineral soils with generally similar textures, while spruce stands were on organic soils (Reich et al. 2001).

\section{METHODS}

At each site, we located a $60 \times 60 \mathrm{~m}$ core study area at least $50 \mathrm{~m}$ from an opening, with 25 points in a $5 \times 5$ grid at 10 -m spacing. Her-
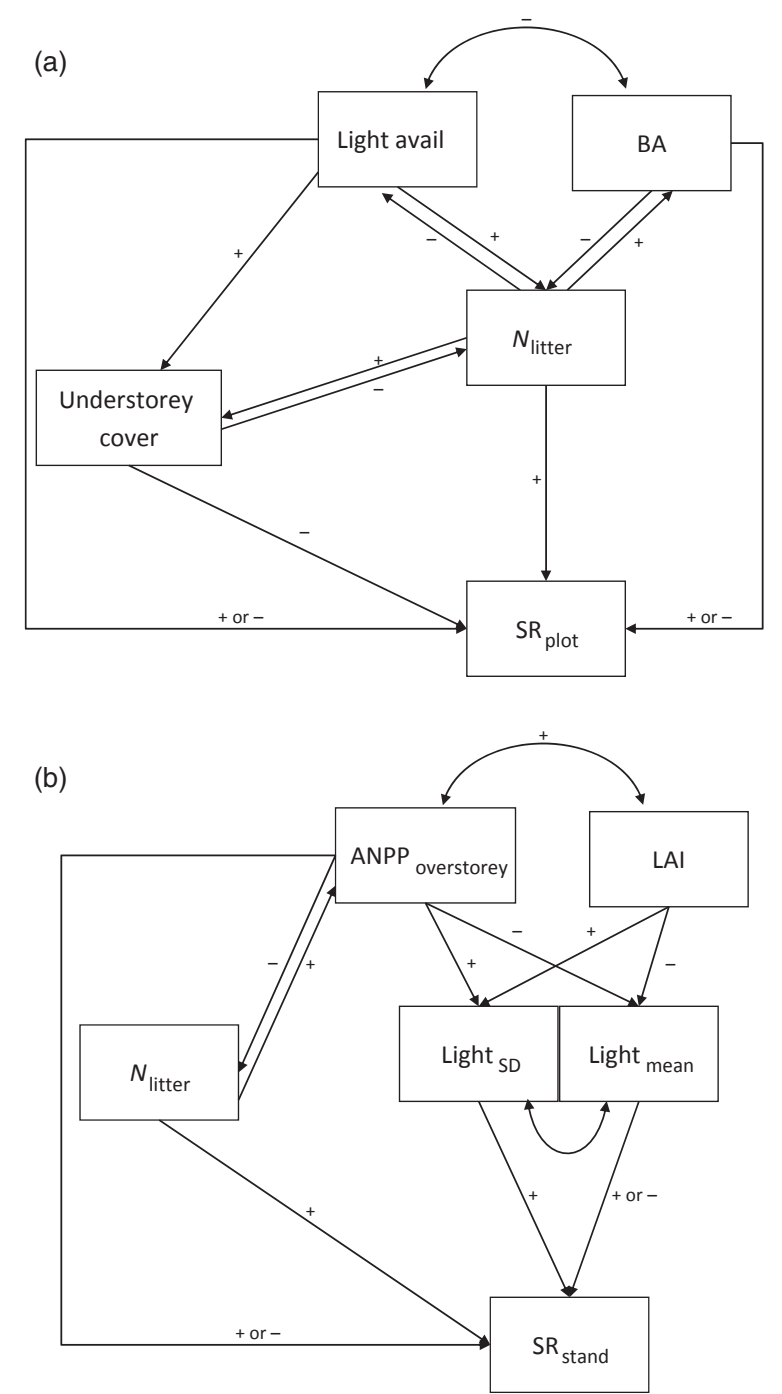

Fig. 1. (a and b) Conceptual models of hypothesized relationships between ANPP and understorey species diversity in southern boreal forests at (a) patch $\left(\mathrm{SR}_{\text {plot }}\right)$ and (b) stand $\left(\mathrm{SR}_{\text {stand }}\right)$ scales. The diagrams are drawn to demonstrate relationships that might arise across a gradient of rising ANPP if overstorey trees influence total vascular plant richness via competitive exclusion. The figure should be interpreted as a cascade of effects. The hypothesized cascade is that high ANPP (or its surrogate high basal area, BA) is associated with high leaf area index (LAI) that results in high canopy light interception and low understorey light availability (and low patchiness of understorey light availability at the stand scale). These lead to low species richness. Low understorey light availability also leads to low abundance of understorey dominants that exert their own competitive exclusion of other understorey species when they are highly abundant; thus, rising ANPP increases species richness by muting the abundance of the understorey dominants. Litter nitrogen concentration ( $\mathrm{N}_{\text {litter }}$; an index of soil nitrogen supply) is positively related to ANPP, BA, LAI, and also directly positively related to understorey diversity. Further explanation of these hypotheses is provided in the text. Curved arrows represent correlations. Straight arrows represent direct relationships. Light $_{\text {mean }}=$ mean light availability across plots. Light $_{\mathrm{SD}}=$ standard deviation of light availability among plots. Light avail. = within-plot light availability. $\mathrm{ANPP}_{\text {overstorey }}=\mathrm{ANPP}$ of the overstorey at the stand scale. 
Table 1. Effects on patch-scale species richness (SR) of the seven understorey species with highest abundance (total cover) across all 2025 plots. The SR effect is from a model run for each species individually that includes light at 1-m height (above the vast majority of all understorey cover), the total understorey cover, and the cover of the species in question, using only plots where the species was present. When the species is significant in relation to SR, the direction of the relationship of its cover to SR is shown. The rank among all species of their relative abundance in cover for those plots where each species was present is shown as well. NS, not significant.

\begin{tabular}{llllll}
\hline Species & Fundance rank & Functional type & SR effect (direction) & $\begin{array}{l}\text { Rank in cover } \\
\text { when present }\end{array}$ & Frequency rank \\
\hline Corylus cornuta & 1 & Shrub & - & 1 & 4 \\
Eurybia macrophylla & 2 & Herb & - & 9 & 2 \\
Maianthemum canadense & 3 & Herb & + & 73 & 1 \\
Cornus canadensis & 4 & Herb & NS & 52 & 3 \\
Abies balsamea & 5 & Tree seedling & - & 4 & 12 \\
Diervilla lonicera & 6 & Shrub & - & 29 & 5 \\
Aralia nudaculis & 7 & Shrub & NS & 28 & 6 \\
\hline
\end{tabular}

baceous, shrub and woody seedling vegetation surveys (presence and percent cover) were made in midsummer at all 25 points using 0.75 m-radius circular plots. Cover was visually estimated for all species lower than $1 \mathrm{~m}$ in height as the vertically projected area, using a sixclass system $(1 \%, 1-5 \%, 6-25 \%, 26-50 \%, 51-75 \%$ and $76-100 \%)$. Abundance was defined by cover, using midpoints of cover classes. Stem counts were made for shrubs (all heights) within a 1-m radius of plot centre. Stems were counted individually up to five and then placed into classes of 6-10, 11-20, 21-50, or $>50$. Tree inventories (species and dbh of all trees $>5 \mathrm{~cm} \mathrm{dbh}$ ) were made on 4.5 -m radius plots centred at all 25 points within every stand.

Annual ANPP and litterfall N cycling of the woody plants were assessed using standard methods (Reich et al. 2001). Litterfall was collected repeatedly using $28 \times 34 \mathrm{~cm}$ traps near ground level over a full year period at 9-15 randomly selected plots in each stand, spatially offset from the herbaceous survey plot centre point, oven-dried and weighed, and analysed for $\mathrm{N}$ concentration (Kjeldahl method, Research Analytical Laboratory, University of Minnesota). Annual woody plant ANPP was assumed to be the sum of wood production and woody plant litterfall production. Annual above-ground wood production was estimated using radial growth in the most recent 10 year and estimates of stemwood biomass based on dbh (see Reich et al. 2001 for details). Although litter traps capture most fine litterfall from tall shrubs, they do not capture litterfall from short herbaceous vegetation and short shrubs. We also did not measure wood production of shrubs. Thus, our values for ANPP slightly underestimate total vascular plant ANPP.

The percentage canopy openness was used as an index of light interception at both plot and stands scales and was measured using a method that contrasts understorey with open photosynthetic photon flux density (PPFD) under diffuse light conditions (Machado \& Reich 1999); all measurements were made at dusk or dawn. Percentage canopy openness measured using this method has been shown to correspond well with median summed instantaneous PPFD in both broad-leafed and needle-leafed forests (Machado \& Reich 1999; Tobin \& Reich 2009). The standard deviation of light among plots in each stand was used as a measure of heterogeneity. Leaf area index (LAI) was estimated at the stand scale by taking litterfall mass, converting it to litterfall area using measured specific leaf area (which equal LAI for aspen stands), and multiplying by leaf life span for the evergreen stands.

Using all data to examine bivariate relations, species richness at the plot scale and at the aggregated stand scale were both negatively correlated with light availability and the abundance of spruce (basal area of spruce), and positively correlated with litter $\% \mathrm{~N}$, aspen basal area, total stand basal area, and ANPP (data not shown). However, these correlations in many cases mask more complex relations and interactions. Hence, we used SEM as an integrated approach to data synthesis (e.g. Oberle, Grace \& Chase 2009; Jonsson \& Wardle 2010).

\section{PLOT-LEVEL MODELS AND ANALYSES}

Total basal area and light availability are linearly correlated with ANPP at the stand scale $(P<0.0001, r=0.60$ and 0.73 , respectively). We therefore used these variables as proxies for plot scale productivity (ANPP and LAI were not measured at the plot scale). Because total basal area accounts for woody biomass while light availability accounts for leaf biomass, we allowed both of these variables to affect our index of $\mathrm{N}$ availability $\left(\mathrm{N}_{\text {litter }}\right.$; Fig. 1a). Similarly, because understorey cover is a measure of productivity that should affect and be affected by $\mathrm{N}$ availability, we also included these pathways in the full model (Fig. 1a).

We fitted the full model (Fig. 1a), to the plot-level data and compared it with versions that removed the pathways between light avail-

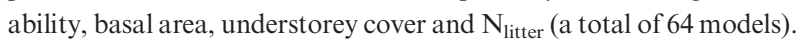
We then took the best model from this set and compared it with models that incorporated forest composition data: black spruce, jack pine, and/or aspen basal area into the model. These models incorporated (i) no composition data, (ii) data for all three species, (iii) data for all combinations of two species, and (iv) data for one of the species (a total of eight models). Species basal area data were allowed to affect light availability, $\mathrm{N}_{\text {litter, }}$, understorey cover, and $\mathrm{SR}_{\text {plot }}$. Because species' basal area was not correlated with basal area of other species but was correlated with the total basal area, all models included correlations between each species' basal area and total basal area (i.e. interspecific basal area correlations were not included). However, adding species composition into the model added little further explanatory power, so these results are not presented.

All models were assessed for goodness-of-fit, using Satorra-Bentler scaled $\chi^{2}$ tests. In this case, $P>0.05$ indicates that model fits produce covariance matrices not significantly different from observed covariance matrices (i.e. indicate of adequate model fit). Models with significant fits were compared using Akaike's Information Criterion (AIC). AIC determines the model closest to the unknown truth, which is represented by the data (Burnham \& Anderson 2002). The model with the lowest AIC value has the most support in the data and is closest to the unknown truth. To be chosen as the best model, the model had to be statistically significant and be more than 3 AIC points away from the next best model. If all significant models that were $<3$ AIC points away from the best model were nested, then the results from the most 
inclusive model (model with the most pathways) are discussed. If these models were not nested, the results from all models are discussed.

All models were fit in $R$ 2.12.0 using proc lavaan (Rosseel 2011). We used maximum likelihood estimation with robust standard errors and a Satorra-Bentler scaled $\chi^{2}$ statistic (MLM estimation) to determine the significance of the models and each model's path coefficients. Calculating AIC values using MLM estimation is problematic (Markon \& Krueger 2004). We therefore used AIC values generated using maximum likelihood estimation (ML) to compare models, with the understanding that the results may be biased and model weights inaccurate. Thus, the AIC results are largely qualitative rather than quantitative.

\section{STAND-LEVEL MODELS AND ANALYSIS}

Examination of the data and the fit of SEM models revealed a strong correlation between mean light availability and the standard deviation (SD) of light availability, as well as the potential for significant effects of ANPP on mean and SD light (in addition to the effects of LAI on these variables; Fig. 1b). Models without these correlations did not significantly fit the data.

We first compared the fit of the full model to (i) a model that omitted the pathway between ANPP and stand-level species richness ( $\left.\mathrm{SR}_{\text {stand }}\right)$, (ii) a model that omitted the pathways between ANPP and the two light variables (SD and mean light), (iii) a model that omitted the pathways between ANPP and the two light variables and ANPP and $\mathrm{SR}_{\text {stand }}$. Removing the pathway between ANPP and $\mathrm{SR}_{\text {stand }}$ tests whether or not the model accounts for the effects of ANPP by including information about light and $\mathrm{N}$ availability.

As above, all models were fit in R2.12.0 using proc lavaan (MLM estimation), assessed for goodness-of-fit using Satorra-Bentler scaled $\chi^{2}$ tests and compared using AIC (ML estimation). As with plot-scale data, the stand-scale analyses were only modestly different if compositional data were included for the overstorey; hence, these results are not presented.

\section{Results}

\section{PLOT LEVEL}

Across all plots and stands, only one model was significant (Fig. 2). In this model, light availability and total basal area were negatively correlated, understorey cover decreased weakly with increasing light availability, $\mathrm{N}_{\text {litter }}$ increased with basal area, basal area declined with increasing $\mathrm{N}_{\text {litter }}$, and $\mathrm{N}_{\text {litter }}$ increased with increasing understorey cover (Fig. 2; $P=0.7627) . \mathrm{SR}_{\text {plot }}$ increased with $\mathrm{N}_{\text {litter }}$ and understorey cover (Fig. 2). Light availability and total basal area had very weak effects on $\mathrm{SR}_{\text {plot }}$ (Fig. 2). The model also included several weak indirect effects on $\mathrm{SR}_{\text {plot }}$ light availability decreased $\mathrm{SR}_{\text {plot }}$ by decreasing understorey cover (indirect path coefficient $=-0.065$ ), total basal area increased $\mathrm{SR}_{\text {plot }}$ by increasing $\mathrm{N}_{\text {litter }}$ (indirect path coefficient $=0.171$ ), and understorey cover increased $\mathrm{SR}_{\text {plot }}$ via increasing $\mathrm{N}_{\text {litter }}$ (indirect path coefficient $=0.116$ ).

Results presented earlier focus on direct and indirect effects of overstorey individuals on resources and hence, on overall species richness. The models demonstrate that understorey cover can also play a role in influencing species richness. Here, we present additional evidence that species richness is negatively

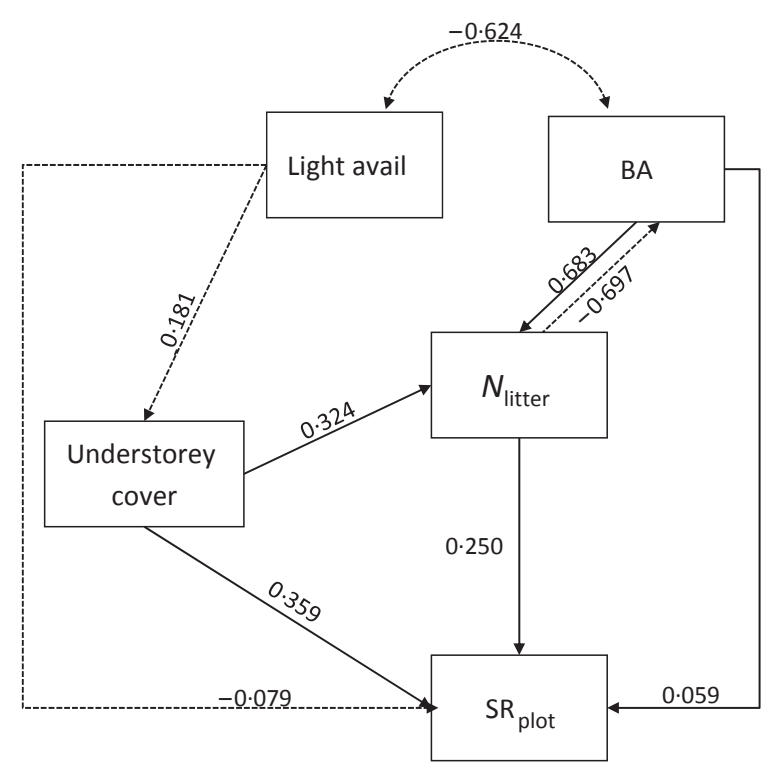

Fig. 2. The best structural equation model (SEM) for the patch (i.e. plot) level diversity data $\left(\chi^{2}=0.091\right.$, d.f. $=1, P=0.7627$; significant models have $P>0.05$ ). Solid black lines indicate direct positive relationships. Dashed black lines indicate direct negative relationships. Curved lines indicate correlations. Straight lines indicate direct relationships. Lightavail $=$ plot-levellightavailability. $\mathrm{N}_{\mathrm{litter}}=$ litter $\mathrm{N}$ content. $\mathrm{SR}_{\text {plot }}=$ plot-level species richness. $\mathrm{BA}=$ basalarea.

related to the abundance of particular understorey species. Given that understorey individuals of each species were not found in every plot, we tested the 25 most abundant species one at a time, only in plots where present, using a simple analytical model that included the cover of the species in question, as well as the total understorey cover and light (to eliminate possible confounding with those variables). Species richness at the plot scale was always highly positively related to total understorey cover, with or without any of the species in the model.

Of the most abundant 25 species, we show results for the seven most abundant (defined using cover summed across all plots, i.e. mean cover when present, multiplied by frequency) that collectively made up almost one-third of total understorey cover across all plots and stands. Relationships of species richness per plot with the cover of individual species were examined independently for each species in turn. For four of these seven abundant taxa (Corylus cornuta Marsh., Eurybia macrophylla (L.) Cass., Abies balsamea (L.) Mill., Diervilla lonicera (Mill.), species richness per plot was significantly and negatively related with their cover (Table 1). Three of these four (Corylus cornuta Marsh., Eurybia macrophylla, and Abies balsamea (L.) Mill.) were among the 10 species with greatest mean cover when present (Table 1). Two of the seven abundant species (Aralia nudicaulis, Cornus canadensis) had non-significant relations, and one species (Maianthemum canadense Desf.) had a significant positive relationship with species richness. However, although $M$. canadense was the most frequent species overall, it was not abundant on average when it was present (ranking among species, 73rd greatest mean cover when present) and was rarely abundant (in $<5 \%$ of the plots it occupied did it have $>5 \%$ cover), so it is difficult to envision a 
mechanism whereby it could influence species richness per plot. Instead this positive relation might indicate that both species richness and Maianthemum canadense cover were responding to similar factors. In contrast, Corylus cornuta, Eurybia macrophylla, Abies balsamea and Diervilla lonicera had $>25 \%$ cover in between $1 / 5$ and $2 / 5$ of all plots where present, so lower species richness in plots where these species had high cover is consistent with a resource pre-emption explanation.

\section{STAND LEVEL}

The full model and the full model minus the pathway between ANPP and $\mathrm{SR}_{\text {stand }}$ fit the data well $(P>0.05)$. However, because these models were $<2$ AIC points apart, we discuss the results from only the more inclusive, full model. Using the full versus reduced model did not change the significance or direction of path coefficients. The remaining two models, which omitted the pathways between ANPP and light availability (mean light) and variability (SD light), did not fit the $\mathrm{SR}_{\text {stand }}$ data significantly.

Increasing $\mathrm{N}_{\text {litter }}$ and light variability (SD) both increased $\mathrm{SR}_{\text {stand }}$ (Fig. 3). ANPP and LAI were strongly positively correlated, while SD and mean light were moderately negatively correlated (Fig. 3). Increasing ANPP decreased mean light, but increased SD light (Fig. 3). ANPP also weakly increased $\mathrm{SR}_{\text {stand }}$ by increasing light variability (indirect path coefficient $=0.192$ ).

\section{Discussion}

The analyses showed that species richness was driven by several direct and indirect processes, as outlined in our conceptual model and the final structural equation models (Figs 1-3). The results are consistent with a classic competitive exclusion explanation, because increasing abundance of the dominant overstorey trees was associated with greater light pre-emption and resulting lower plot-scale richness.

However, other indirect pathways involving both nitrogen and light also contributed to impacts on species richness. First, nitrogen availability at the plot scale was positively influenced by productivity and in turn positively influenced species richness. Thus, impacts of overstorey dominants on species richness could follow alternate and offsetting pathways. Second, impacts of decreasing light availability also influenced understorey species richness indirectly by reducing the cover of the overall understorey community, offsetting to some degree the competitive exclusion by the overstorey. The evidence suggests that these effects are likely due to the most abundant and common species, which appear to negatively influence understorey species richness. It is possible that with increasing tree abundance, understorey plants had less access to all resources, including light, water, and nutrients, the latter two which were not measured sufficiently in this context to address further from these data.

As hypothesized, the presence at high abundances of several of the more common understorey species suppressed plot-scale species richness, with their abundance in turn suppressed by high productivity and density of the overstorey species. This is

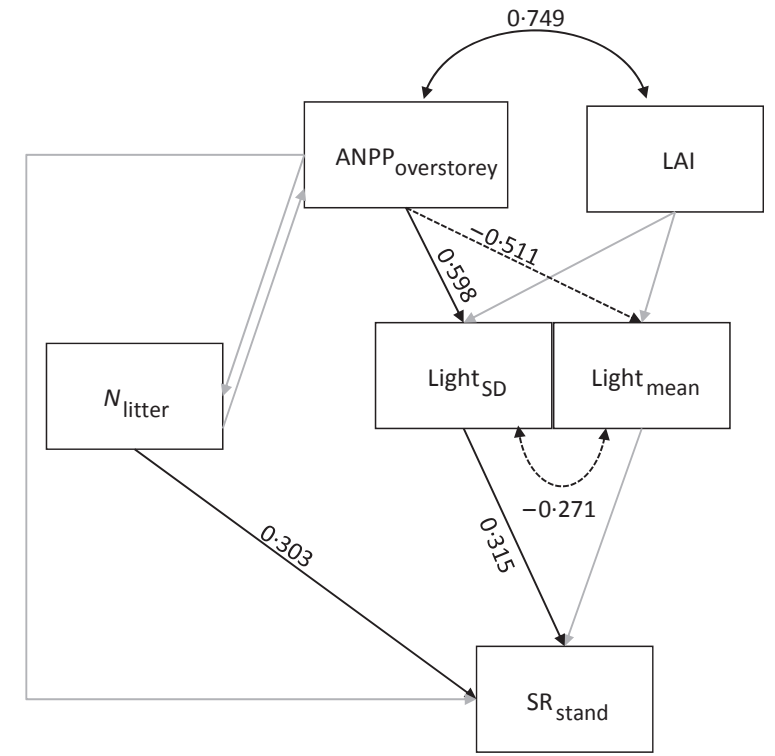

Fig. 3. The full structural equation model (SEM) for the stand-level diversity data $\left(\chi^{2}=6.094\right.$, d.f. $=3, P=0.1071$; significant models have $P>0.05$ ). Solid black lines indicate direct positive relationships. Dashed black lines indicate direct negative relationships. Gray lines indicate non-significant relationships. Curved lines indicate correlations. Straight lines indicate direct relationships. Light $_{\text {mean }}=$ mean light availability across plots. Light SD $=$ standard deviation of light availability among plots. $\mathrm{ANPP}_{\text {overstorey }}=\mathrm{ANPP}$ of the overstorey at the stand scale. LAI $=$ leaf area index.

consistent with detailed results for two intensively studied plots which showed that Aralia nudicaulis L., Maianthemum canadense and Eurybia macrophylla were negatively correlated with, and presumably pre-empted by Corylus cornuta (Frelich, Machado \& Reich 2003). In addition, the species that caused negative impacts in richness when abundant are relatively large in stature, or in the case of E. macrophylla, has large leaves, so that physical and/or resource pre-emption are more likely than for species with smaller individuals, such as $M$. canadense.

Our data also suggest that light heterogeneity plays a significant role in influencing stand-scale species richness, as high productivity led to greater light heterogeneity which enhanced stand-scale richness. High patch-scale heterogeneity of light equates with a higher diversity of micro-sites that as a consequence may be occupied by a greater diversity, in aggregate, of species.

One hypothesized effect (positive influence of litter $\% \mathrm{~N}$ on basal area) was significant in the opposite direction at the plot scale (Fig. 2). This negative relationship is non-intuitive, especially given a positive impact of basal area on litter $\% \mathrm{~N}$. These plot-scale patterns could plausibly occur if impacts of basal area on litter $\% \mathrm{~N}$ represent largely a stand-scale relationship (i.e. stands with high productivity on average have higher litter $\% \mathrm{~N}$ on average), whereas relations of litter $\% \mathrm{~N}$ to basal area at plot scale are driven more by heterogeneity in basal area among plots. Given that patches (i.e. plots) with low basal area have higher understorey cover of deciduous angiosperm shrubs and herbs and thus are likely to have high litter $\% \mathrm{~N}$ (Fig. 2), this could lead to a negative statistical impact of litter $\% \mathrm{~N}$ on basal area at the plot scale. Although we can only spec- 
ulate about this effect, it is largely tangential to the hypothesized and demonstrated cascade of effects on species richness and hence, has little impact on the overall results or interpretation of the study.

The stand-scale results are associated with differences among the sampled forests. Low productivity aspen stands (e.g. ANPP c. 2-3 $\mathrm{Mg} \mathrm{ha}^{-1}$ year $^{-1}$ ), which tend to be open and relatively nutrient-rich, generally had the highest species richness at both plot and stand scales, consistent with interpretation of Hart \& Chen (2008). Intermediate stand-scale species richness was found in high productivity sites (e.g. ANPP $>4 \mathrm{Mg} \mathrm{ha}^{-1}$ year $^{-1}$ ) of all three forest types, where light levels penetrating to the understorey were lowest. The lowest standscale species richness occurred in low productivity (ANPP $<3 \mathrm{Mg} \mathrm{ha}^{-1}$ year $^{-1}$ ) black spruce stands that had greater understorey light availability but lower light heterogeneity than more productive spruce stands. Such stands likely represent the situation in which very low resource availability (nutrients rather than light) and high environmental stress (e.g. waterlogging and high acidity) combine to limit the number of species able to successfully tolerate local conditions.

At both the plot and stand scale, increasing resource availability and/or heterogeneity largely accounted for the relationships between ANPP and SR. At the stand level, accounting for $\mathrm{N}_{\text {litter }}$ and light heterogeneity resulted in a non-significant residual relationship between $\mathrm{ANPP}$ and $\mathrm{SR}_{\text {stand; }}$; at the plot level, accounting for resource availability resulted in productivity (or the proxies used in the model) having extremely weak effects on $\mathrm{SR}_{\text {plot }}$.

In summary, our findings showed that indirect effects of overstorey dominants can both amplify and dampen the effects of light pre-emption on understorey species richness. These results suggest that simple hypotheses should address multiple networked pathways (e.g. Jonsson \& Wardle 2010) to best assess responses in complex systems such as plant communities.

\section{Acknowledgements}

We thank the members of our summer research teams for assistance with field sampling, the Wilderness Research Foundation for financial support, and J.B. for statistical consultation.

\section{References}

Burnham, K.P. \& Anderson, D.R. (2002) Model Selection and Multimodel Inference: A Practical Information-Theoretic Approach Springer-Verlag.

Chase, J.M. (2010) Stochastic community assembly causes higher biodiversity in more productive environments. Science, 328, 1388-1391.

Chase, J.M. \& Leibold, M.A. (2002) Spatial scale dictates the productivity-biodiversity relationship. Nature, 416, 427-430.

Chase, J.M. \& Leibold, M.A. (2003) Ecological Niches. Linking Classical and Contemporary Approaches. University of Chicago Press, Chicago.

Chen, H.Y.H., Legare, S. \& Bergeron, Y. (2004) Variation of the understory composition and diversity along a gradient of productivity in Populus tremuloides stands of northern British Columbia, Canada. Canadian Journal of Botany, 82, 1314-1323.

Chipman, S.J. \& Johnson, E.A. (2002) Understory vascular plant species diversity in the mixedwood boreal forest of Western Canada. Ecological Applications, 12, 588-601.

Frelich, L.E., Machado, J. \& Reich, P.B. (2003) Fine-scale environmental variation and structure of understory plant communities in two old-growth pine forests. Journal of Ecology, 91, 283-293.
Gillman, L.N. \& Wright, S.D. (2006) The influence of productivity on the species richness of plants: a critical assessment. Ecology, 87, 1234-1243.

Grime, J.P. (1977) Evidence for the existence of three primary strategies in plants and its relevance to ecological and evolutionary theory. American Naturalist, 111, 169-1194.

Gross, K.L., Willig, M.R., Gough, L., Inouye, R. \& Cox, S.B. (2000) Patterns of species density and productivity at different spatial scales in herbaceous plant communities. Oikos, 89, 417-427.

Haeussler, S. \& Bergeron, Y. (2004) Range of variability in boreal aspen plant communities after wildfire and clear-cutting. Canadian Journal of Forest Research, 34, 274-288.

Hart, S.A. \& Chen, H.Y.H. (2006) Understory vegetation dynamics of North American boreal forests. Critical Reviews in Plant Sciences, 25, 381-397.

Hart, S.A. \& Chen, H.Y.H. (2008) Fire, logging and overstory affect understory abundance, diversity, and composition in boreal forest. Ecological Monographs, 78, 123-140.

Huston, M. (1979) A general hypothesis of species diversity. American Naturalist, 113, 81-101.

Jonsson, M. \& Wardle, D.A. (2010) Structural equation modelling reveals plant community drivers of carbon storage in boreal forest ecosystems. Biology Letters, 6, 116-119.

Kembell, K.J., Wang, G.G. \& Dang, Q.L. (2005) Response of understory plant community of boreal mixedwood stands to fire, logging, and spruce budworm outbreak. Canadian Journal of Botany, 83, 1550-1560.

Legare, S., Bergeron, Y., Leduc, A. \& Paré, D. (2001) Comparison of the understory vegetation in boreal forest types of southwest Quebec. Canadian Journal of Botany, 79, 1019-1027.

Machado, J.L. \& Reich, P.B. (1999) Evaluation of several measures of canopy openness as predictors of photosynthetic photon flux density in deeply shaded conifer-dominated forest understory. Canadian Journal of Forest Research, 29, 1438-1444.

Markon, K.E. \& Krueger, R.F. (2004) An empirical comparison of information-theoretic selection criteria for multivariate behavior genetic models Behavior Genetics, 34, 593-610.

Mittelbach, G.G., Steiner, C.F., Scheiner, S.M., Gross, K.L., Reynolds, H.L., Waide, R.B., Willig, M.R., Dodson, S.I. \& Gough, L. (2001) What is the observed relationship between species richness and productivity? Ecology, 82, 2381-2396.

Newman, E.I. (1973) Competition and diversity in herbaceous vegetation. Nature, 244, 310-311.

Oberle, B., Grace, J.B. \& Chase, J.M. (2009) Beneath the veil: plant growth form influences the strength of species richness-productivity relationships in forests. Global Ecology and Biogeography, 18, 416-425.

Rajaniemi, T.K. (2003) Explaining productivity-diversity relationships in plants. Oikos, 101, 449-457.

Rees, D.C. \& Juday, G.P. (2002) Plant species diversity on logged versus burned sites in central Alaska. Forest Ecology and Management, 155, 291-302.

Reich, P.B. (2009) Elevated $\mathrm{CO} 2$ reduces losses of plant diversity caused by nitrogen deposition. Science, 326, 1399-1402.

Reich, P.B., Bakken, P., Carlson, D., Frelich, L., Friedman, S. \& Grigal, D.F. (2001) Influence of logging, fire, and forest type on biodiversity and productivity in southern boreal forests. Ecology, 82, 2731-2748.

Rosseel, Y. (2011). Lavaan: Latent Variable Analysis. R package version 0.3-3. http://CRAN.R-project.org/package = lavaan (accessed 11 July 2011).

Shipley, B. (2002) Cause and Correlation in Biology: A User's Guide to Path Analysis, Structural Equations and Causal Inference. Cambridge University Press, Cambridge.

Tilman, D. \& Pacala, S.W. (1993) The maintenance of species richness in plant communities. Species Diversity in Ecological Communities (eds R. Rickleffs \& D. Schluter), pp. 13-25. University Press, Chicago.

Tobin, M. \& Reich, P.B. (2009) Comparing indices of understory light availability between hemlock and hardwood forest patches. Canadian Journal of Forest Research, 39, 1949-1957.

Waide, R.B., Willig, M.R., Steiner, C.F., Mittelbach, G.G., Gough, L. \& Dodson, S.I. (1999) The relationship between productivity and species richness. Annual Review of Ecological Systems, 30, 257-300.

Walters, M.B. \& Reich, P.B. (2000) Trade-offs in low-light CO2 exchange: a component of variation in shade tolerance among cold temperate tree seedlings. Functional Ecology, 14, 155-165.

Wardle, D.A., Zackrisson, O., Hörnberg, G. \& Gallet, C. (1997) The influence of island area on ecosystem properties. Science, 277, 1296-1299.

Received 21 June 2011; accepted 17 October 2011

Handling Editor: Hans Jacquemyn 